\title{
OBTENÇÃO DE BIOMASSA E HIDROGÊNIO USANDO FOTOBIORREATORES
}

\author{
AUTOR: RODRIGO GUIMARAES DE DEUS \\ CO-AUTOR/ORIENTADOR: ORLANDO ERNESTO JORQUERA CORTES
}

Resumo: A produção de hidrogênio $(\mathrm{H} 2)$ se apresenta como uma alternativa energética renovável pois sua combustão é limpa, gerando como resido apenas água, além de possuir uma boa relação entre geração de energia e massa e fácil conversão para energia elétrica. Algumas microalgas do gênero Chlorella vem sendo utilizada em pesquisas pois possuem a capacidade de produzir $\mathrm{H} 2$ quando inseridas em um meio de cultura sem enxofre. Este projeto visou o estudo, avaliação e otimização de crescimento, produção de $\mathrm{H} 2$ e parâmetros de operação do fotobiorreator no cultivo de microalgas Chlorella vulgaris, além da elaboração de um guia sobre o cultivo das microalgas. As cepas foram acondicionadas em local com iluminação constante e pequenas amostras retiradas foram cultivadas em meio líquido standard Tris-Acetato-Fosfato (TAP). Um fotobioreator foi montado seguindo projetos anteriores, e foram monitorados parâmetros como pH, temperatura, biomassa in linha (absorvância), pressão, vazão de ar e de N2 e H2 na fase gás, utilizado o programa LabView acoplado a um conversor análogo digital. Para a elaboração do guia foram consultadas fontes reconhecidas academicamente e o caderno de campo do laboratório. No meio TAP, as microalgas apresentaram uma taxa de crescimento específico (TCE) de 0,0296 h-1, ao comparar o meio TAP com o meio industrial o tempo de duplicação (TD) diminuiu $64,9 \%(15,187)$ e a TCE aumentou 55,4\% (0,046 h-1). O guia, ainda não finalizado, já conta com 4 capítulos elucidando os principais aspectos do cultivo de microalgas, e encontra-se em processo de formatação. Esse trabalho evidencia o potencial do meio de cultura TAP para a produção de hidrogênio e biomassa, já o guia terá grande importância para a continuação desse, e de novos projetos, uma vez que os próximos pesquisadores terão uma base solida sobre os experimentos realizados.

Palavras-chave: Produção de hidrogênio, guia de cultivo, Fotobioreator. 